\title{
The implications for patients undergoing splenectomy: postsurgery risk management
}

This article was published in the following Dove Press journal:

Open Access Surgery

3I August 20 I I

Number of times this article has been viewed

\section{Fabrizio Romano \\ Mattia Garancini \\ Arianna Libera Ciravegna \\ Fabio Uggeri \\ Luca Degrate \\ Matteo Maternini \\ Franco Uggeri}

Department of General Surgery (Chirurgia I), San Gerardo Hospital, University of Milan-Bicocca, Monza, Italy
Correspondence: Fabrizio Romano Assistant Professor of Surgery, San Gerardo Hospital, University of Milan-Bicocca,Via Donizetti 106, 20900 Monza, Italy

Tel +390392333600

Email fabrizio.romano@unimib.it

\begin{abstract}
Splenectomy has been performed for a heterogeneous group of hematologic diseases with a therapeutic or diagnostic purpose or as part of the staging process in Hodgkin's disease. Most patients undergoing therapeutic splenectomy are chronically ill with significant splenomegaly. This scenario can be associated with a high risk of postoperative morbidity and mortality due to the prolonged course of disease for patients with myelofibrosis; their susceptibility to infection, thrombosis, and hemorrhage; and the severe enlargement of their spleens. We have reviewed the main papers published about postoperative complications after splenectomy, analyzing the risk factors, prevention measures, and respective treatments. Great care must be taken in the management of patients presenting malignant diseases, splenomegaly, and hemostasis disorder. Moreover, despite the faster discharge that new surgical techniques now allow, close attention should be paid to symptoms reported by patients, in order to avoid potentially life-threatening complications such as portal vein thrombosis, pancreas injuries, and overwhelming postsplenectomy infection.
\end{abstract}

Keywords: hematologic disease, complications, postoperative, laparoscopic

\section{Introduction}

Elective splenectomy continues to play a role in the management of hematologic diseases. ${ }^{1-3}$ Splenectomy has been performed for a heterogeneous group of hematologic diseases with a therapeutic or diagnostic purpose or as part of the staging process in Hodgkin's disease. Splenectomy has proved to be safe and effective in selected patients presenting non-Hodgkin's lymphoma, idiopathic thrombocytopenic purpura, thrombotic thrombocytopenic purpura, and hairy cell leukemia. Current trends in the management of Hodgkin's and non-Hodgkin's lymphoma have led to a decrease in the frequency of splenectomy for staging purposes. ${ }^{4,5}$ The most common indications for therapeutic splenectomy are bulk symptoms and cytopenias. With the exception of idiopathic thrombocytopenic purpura, most patients undergoing therapeutic splenectomy are chronically ill with significant splenomegaly. ${ }^{6,7}$ This scenario can be associated with a high risk of morbidity and mortality. Among patients presenting myeloproliferative malignancies, the benefits of splenectomy must be carefully weighed against the risk of surgery and the patient's limited life expectancy. ${ }^{8-12}$ Myelofibrosis and myeloid metaplasia have been historically associated with higher morbidity and mortality after splenectomy when compared with other hematologic disorders. ${ }^{8,10}$ The prolonged course of disease for patients with myelofibrosis; their susceptibility to infection, thrombosis, and hemorrhage; and the severe enlargement of their spleens have been described as factors that increase postoperative complication rates. 
Numerous retrospective studies have demonstrated the dangers of splenectomy for certain high-risk disease states. ${ }^{8,12}$ The decision to proceed with splenectomy should involve careful consideration of its potential risks and benefits. Several retrospective studies of splenectomy for hematologic disease show complication rates that range between $13 \%$ and $52 \%$, with mortality rates ranging from $1 \%$ to $9 \%{ }^{1,4,8,9}$ Musser et al ${ }^{1}$ reported a complication rate of $25 \%$ and a $5 \%$ mortality rate in 306 splenectomies performed at the University of California, Los Angeles, with 19\% of the procedures performed for diagnostic reasons only. The authors also acknowledge that significantly fewer complications were observed in patients undergoing diagnostic splenectomy. Dawson et $\mathrm{al}^{2}$ reported a morbidity of $25 \%$ with a $1 \%$ mortality rate among 185 patients, $45 \%$ of whom were affected by Hodgkin's disease. Similarly, Johansson etal ${ }^{3}$ described various complications in $14.5 \%$ of 200 splenectomies with a mortality rate of $1 \%$. Again, $38 \%$ of those splenectomies were performed with staging purposes for Hodgkin's disease.

Many recent reports describe the benefits of laparoscopic splenectomy (LS), and LS is today the gold standard for any patient suffering from hematological benign diseases requiring splenectomy, except for rare cases due to massive splenomegaly (with high splenic size index) and patient body mass index (BMI). ${ }^{13}$ Most of the reported data during these years reflect a good outcome in terms of both effectiveness and safety. This surgical procedure presents a low rate of total complications (16\%, ranging from $3 \%$ to $20 \%$ ) and postoperative mortality (average rate $1 \%-4 \%$, up to $25 \%$ in cases of splenectomy due to malignancies). ${ }^{14,15}$ However, we must not forget that patients undergoing splenectomy present a strong reduction of their immunocompetence due to their hematological disease and related to the immunosuppressive therapy they receive, and therefore need proper postsurgery risk management.

Complications, which can occur in the early or late postoperative phase, may include pulmonary complications $(3.8 \%)$, wounds $(1.6 \%)$, infections $(1 \%)$, subphrenic abscess $(0.7 \%)$, bleeding (1.6\%), gastrointestinal (1.5\%), pancreatic $(0.6 \%)$, cardiac $(0.3 \%)$, thrombotic $(0.9 \%)$, neurologic $(0.2 \%)$, and genitourinary $(0.4 \%),{ }^{16}$ and sometimes after the open approach, as observed by several authors, can be life-threatening. ${ }^{17}$ Reduction of the wound infection rate is very important, as patients undergoing splenectomy are often immunocompromised.

LS, compared with the open technique, has proved to be the best choice in terms of less postoperative pain, faster recovery, and minor blood loss, together with less morbidity and wound infections, improved pulmonary function, early return to normal bowel function, decreased morbidity, and improved cosmetic results. ${ }^{18,19}$ Morbidity rates rise to $14 \%-50 \%$ in open splenectomy (OS) and to $20 \%-60 \%$ in splenomegaly cases treated with OS, but morbidity rates are comparable with normal cases when applying LS. ${ }^{2}$ Moreover, whereas most laparoscopic studies reported minor complications such asileus, seromas of the port site, and pleural effusion, OS presents a high prevalence of severe complications such as subphrenic abscess requiring surgery (3\%-5\%), severe bleeding (5\%-7\%), and pulmonary embo$\operatorname{lism}(2 \%-6 \%){ }^{20}$

Finally, LS reduces intraoperative risk and postoperative complications most of all in older patients or patients presenting either comorbidity, malignancies, splenomegaly, or other factors that would lead us to consider them at high risk. $^{21}$

The aim of our study was to compare other authors' experiences, with reference to postoperative complications, by analyzing risk factors encountered and identified as the major causes of such complications and considering the preand postoperative management of the splenectomized patient in order to avoid and treat any possible complication.

\section{Methods}

A MedLine search was carried out for all English language reports that used the terms "splenectomy" or "laparoscopic splenectomy and complication" from January 1986 to November 2010. Surgical studies describing risk factors and outcomes of OS and LS have been reviewed in detail, and all references have been examined in order to find additional articles not identified by the MedLine search. Studies were excluded if any of the following parameters were present: fewer than 30 cases, traumatic or incidental splenectomy, data not reported on an intention-to-treat basis, or insufficient details regarding postoperative complications. Both adult and pediatric studies were included. Data extracted from each report include demographic data related to the disease, perioperative details, risk factors, and postoperative complications.

In order to write our review, we decided to include articles on both open and laparoscopic surgery, although most of the recent work we have analyzed refers only to the laparoscopic technique.

\section{Patients at high risk of developing postoperative complications}

The main risk factors have been studied by several authors. In 2000, Targarona et $\mathrm{al}^{22}$ wondered whether age, sex, BMI, 
malignant nature of the hematological disease, preoperative hematocrit and platelet count, operative time, operative position, need of accessory incision, transfusion status, learning curve, and existence of comorbidity could be considered independent risk factors. Their first analysis showed that the age of the patient (youngest and oldest patients are those at highest risk), malignancies, transfusional status, and spleen weight were to be considered independent factors enhancing the risk of complications. Moreover, Targarona's study underlined how such complications were technique related and demonstrated the existence of a learning curve. On the contrary, 1 year later, Cusick and Waldhausen ${ }^{23}$ proved that all complications verified in their cases were rare and spaced out over the entire study series. Therefore, no trend regarding the complication rate was identified. Only blood loss decreased with time primarily because of the technical improvements. However, morbidity and mortality rates may remain at low levels in experienced hands and thanks to the use of up-to-date technological devices. ${ }^{24}$

The most powerful predictor of morbidity is spleen weight, as already confirmed by Boddy et al, ${ }^{25}$ who showed that the odds of morbidity were increased 14-fold in patients with a splenic weight exceeding $1 \mathrm{~kg}$. This means that although LS is feasible on a splenomegalic patient presenting morbidity, transfusion rate, and mean hospitalization rates comparable with those for the open technique, ${ }^{26}$ splenomegaly represents a risk factor for postoperative complications. LS is also feasible in patients with a giant spleen, but it is associated with greater morbidity, and the advantages of minimal access surgery are not so clear. The odds of morbidity increased by $0.1 \%$ each $100 \mathrm{~g}$ in splenic weight above $1000 \mathrm{~g}$ and five-fold for men compared with women. LS among patients with massive splenomegaly has a $0 \%$ mortality rate, $33 \%$ major morbidity, and $22 \%$ minor morbidity rate. Moreover, Patel et $\mathrm{al}^{27}$ demonstrated that splenic weight is correlated to malignant diagnosis, white cell count, and blood loss, highlighting a longer hospital stay in patients with spleens above $1000 \mathrm{~g}$.

McAneny et $\mathrm{al}^{28}$ do not agree. They showed in a metaanalysis that after adjusting for age and diagnosis using multivariate analysis, spleen size was not a risk factor.

According to Casaccia et al, ${ }^{24}$ malignancy is the only preoperative clinical parameter found to be predictive for both conversion to laparotomy and a complicated postoperative course. Even diaphragm lesions with a $0 \%-14 \%$ rate $^{26,29,30}$ are influenced by malignancy, as they are often due to inflammatory and neoplastic perisplenitis.

Splenomegaly and neoplastic perisplenic inflammation (conversion rate for HM patients reaches $11.7 \%$ in the Italian
Register of Laparoscopic Surgery of the Spleen [IRLSS] study) ${ }^{31}$ can be seen as a risk factor even though they represent a cause of conversion to the open technique. Casaccia et $\mathrm{al}^{32}$ show that surgical conversion is a strong predictor for the occurrence of postoperative complication, leading to a frequency of morbidity that is three times higher compared with patients without surgical conversion. Targarona ${ }^{33}$ noticed that in spleens weighing 400-1000 g, conversion rates were 0 ; however, rates were $25 \%$ and $75 \%$ for spleens weighing more than $1000 \mathrm{~g}$ and $3000 \mathrm{~g}$, respectively. Romano et $\mathrm{al}^{34}$ underlined that intraoperative bleeding (particularly in thrombocytopenic patients) is the main complication and main cause of conversion during LS. We obtained an average value of blood loss of $80 \mathrm{~mL}$, whereas the average blood loss was more than $250 \mathrm{~mL}$ using the LigaSure vessel sealing system (Valleylab, Boulder, CO), even in pediatric patients. ${ }^{35}$ Good practice would be to deflate the pneumoperitoneum, wait a few minutes, and inflate a second time in order to control the hemostasis, avoiding the risk of a false absence of bleeding due to the increased pressure of the abdomen. ${ }^{36}$

Moreover, Keidar et $\mathrm{al}^{37}$ suggest that preoperative hemoglobin and platelet count may also play a role in postoperative morbidity and that even if this has no statistical significance, severe anemia and a very high or very low platelet count will surely influence the physical response to surgery, as well as what happens in a patient who is subject to prolonged corticosteroid therapy. In fact, in Casaccia et al's ${ }^{24}$ study, in the group of patients affected by idiopathic thrombocytopenic purpura, some pulmonary, urinary, and skin incision infections and some hemoperitoneum or abdominal fluid collection can be explained by long-term administration of steroids and a low platelet count.

Dominguez et $\mathrm{al}^{38}$ tried to demonstrate that BMI was a risk factor, but the differences between the $>40$ BMI group and the $<40$ BMI group were not statistically significant. In the first study performed on the IRLSS dataset by Casaccia et al, ${ }^{31} \mathrm{BMI}$ had a low impact on intraoperative and immediate postoperative LS outcome, but in the second study in $2010,{ }^{32}$ BMI played a major role in affecting the LS intraoperative outcome.

Problems due to obesity are more evident if an obese patient undergoes anterior approach splenectomy, where the appropriate retraction of the spleen must be performed against gravity, which leads to more capsular tears, increased blood loss, transfusion rates, and conversion rates. ${ }^{19}$

Rescorla and Frederick ${ }^{39}$ observed higher complication rates in children with sickle cell disease (SCD) undergoing $\mathrm{LS}$, with a $10 \%$ acute chest syndrome (ACS) rate despite 
prophylactic treatment and a longer length of stay. Hematologists have discouraged the administration of prophylactic aspirin for thrombocytosis in children, but the authors suspect that hematologists may have underrecognized this complication.

\section{Postoperative complications}

Possible postsplenectomy complications may be due to the surgery itself or to the consequent aspects of the asplenic condition.

Early complications (Tables 1 and 2) related to surgical procedures can be divided into two categories:

- Minor (grade I and II of the Clavien-Dindo classification), requiring pharmacological treatment or resulting in spontaneous recovery, through a longer hospitalization (often due to equipment malfunctioning). ${ }^{40}$ Complications include fever, wound pain, and pain reflected to the left shoulder due to pneumoperitoneum, pleural effusion, and atelectasis showing regression after respiratory physiotherapy (10.6\%), bronchopneumonia (BPN) (9.1\%), portal or splenic vein thrombosis (PSVT) $(8 \%)$, wound infection treated with antibiotics $(4.5 \%)$, isolated hyperamylasemia, mild pancreatitis (4\%), and minor blood collection spontaneously reduced

- Major (grade III and IV of the Clavien-Dindo classification), which are considered quite rare, requesting a more invasive treatment (often related to bleeding). Complications include blood collection (1\%) and subphrenical abscess $(2.5 \%)$, wound infection requiring evacuation, pleural and peritoneal effusion needing drainage, gastric distension and a dynamic ileus, pancreatic fistula, abdominal organ lesion (stomach 1\%, colon, diaphragm 0\%-14\%), bleeding, and PSVT complicated by bowel infarction.

\section{Bleeding}

Bleeding is the most common intraoperative complication, with an incidence ranging from $1.9 \%$ to $20 \%$ in several studies (averaged rate $6.7 \%$ ), most of all in the first postoperative 24 hours. Bleeding makes up $80 \%$ of causes for conversion to OS. ${ }^{17,41}$ In addition, it is the most common reason for a "second look" operation in the immediate postoperative phase. In the meta-analysis study reported by Winslow and Brunt, ${ }^{16}$ the rate of hemorrhagic complications, when conversion to OS was not necessary, was not significantly different between the OS $(2.4 \%)$ and LS $(1.6 \% ; P=$ not significant $[\mathrm{NS}])$. However, when conversion for bleeding was included as a hemorrhagic complication in the same study, the LS group showed a higher incidence $(4.8 \%)$, with a statistically significant difference with the open group $(P<0.01)$. The conversion rate for bleeding during LS in splenomegaly is significantly higher compared with LS performed in a normal size spleen. Even if compared with OS, LS in an enlarged spleen seems to be associated with lower morbidity, lower transfusion rate, and shorter hospital stay. ${ }^{26}$

\section{PSVT}

PSVT is one of the most important and possibly underestimated complications. A high index of suspicion, early diagnosis, and prompt anticoagulation therapy are key to a successful outcome.

Targarona $^{42}$ noticed that studies published from 1993 to 2006 showed that the incidence of PSVT ranged from $0.9 \%$ to $52 \%$. The reason for this variability lies in two main facts: first, some studies included splenectomy for trauma, whereas others included only hematological cases, with more or less malignant cases; and, second, the diagnosis of PSVT for some authors was a clinical diagnosis (so, only of symptomatic cases), whereas for others a diagnosis was based on lab tests or imaging.

The impact of the underlying disease process on the incidence of PVT after splenectomy is highlighted by an analysis of splenectomized patients with myeloproliferative disorders in which the incidence of PVT after splenectomy was $17.9 \%$; in the study by Broe et al, only symptomatic portal vein thrombosis was reported. ${ }^{43}$

Some groups have demonstrated an incidence of PVT, as detected by routine postoperative imaging, of $7 \%-10 \%$. In retrospective studies of postoperative imaging surveillance for detection of PSVT, Petit et al ${ }^{44}$ reported this event in $10.9 \%$ of cases, and Loring et $\mathrm{al}^{45}$ reported it in $9.8 \%$ of cases with $20 \%-40 \%$ of asymptomatic patients. Loring et al retrospectively reviewed all postoperative imaging studies (ultrasonography, computed tomography [CT], or magnetic resonance imaging) of patients who had undergone splenectomy for hematologic disease and found that $50 \%$ of patients with myelofibrosis/myelodysplastic disorders developed PVT after splenectomy.

In Romano et al's ${ }^{46}$ and Winslow et al's ${ }^{47}$ study, the incidence is among $8 \%$, an higher rate compared to most previously published studies. The main reason explaining this higher rate is that in both studies we could find no splenectomies for trauma but only splenectomy for hematological disease, where PSVT risk is higher.

PSVT may occur right after surgery or up to 3 years later (the average time between onset of symptoms 
and diagnosis of PSVT is 6 days \pm 3.5 days). Prospective studies have found the median time from splenectomy to asymptomatic PSVT to be 6 days ${ }^{48}$ whereas the median interval from splenectomy to symptomatic PSVT ranged from 8 to 12 days in case studies and in retrospective studies. ${ }^{49}$ With the majority of symptomatic PSVT occurring between the first and second week, it is likely to record a latency period between the development of PSVT and the onset of symptoms. However, cases that arose $2-4$ months post-LS may not be strictly related to splenectomy but rather to other local precipitating factors or prothrombotic disorders (eg, malignancy, spherocytosis).

Ikeda et $\mathrm{al}^{50}$ classified PSVT into five types: distal splenic vein thrombosis (dSVT), proximal splenic vein thrombosis (pSVT), superior mesenteric vein thrombosis (SMVT), intrahepatic vein thrombosis (iPVT), and extrahepatic vein thrombosis (ePVT).

PVT (intrahepatic and extrahepatic) is the most common site; the second is the splenic stump of the third mesenteric vein. The greatest risk for serious complications occurs when involvement of the extrahepatic portal vein or total splenic vein thrombosis interfere with flow from the inferior and superior mesenteric vein. Thus, patients with total splenic vein thrombosis are thought to have a poor prognosis and may be at greater risk of developing clinical symptoms compared with patients with other PSVT. ${ }^{51}$

In fact, PSVT may be asymptomatic or may resolve spontaneously, depending on the extent of the thrombus. Isolated splenic stump or partial intrahepatic PVT can be asymptomatic. Portal or mesenteric extension will increase the severity of the clinical picture. Often, patients with PSVT complain of decreased appetite (88\%), more severe than expected abdominal pain (75\%), and malaise (63\%). A few cases show tenderness on abdominal examination. Other symptoms are nausea, fever, ileus, diarrhea, jaundice, and ascites. They can all be misunderstood for classical postoperative symptoms or even of pancreatitis. With laboratory testing, the most common signs are leukocytosis and elevated platelet counts. In the initial phase of PSVT, liver function test findings are within normal limits, whereas serum lactate dehydrogenase levels are elevated. ${ }^{52}$ Accurate diagnosis can usually be made by imaging methods, such as color Doppler ultrasonography, contrast-enhanced CT, or magnetic resonance tomography. Whether CT imaging is superior to ultrasound in this setting is not clear. The detection rate of thrombosis may be low because imaging is highly dependent on operator skill and because vision may be limited in cases of morbid obesity or bowel distension in the first days after surgery. CT with intravenous contrast does not establish the diagnosis of PVT, but it can exclude other intra-abdominal complications.

Early consequences of PSVT are mesenteric thrombus, acute hypertension in the splanchnic circulation, bowel infarction and necrosis, hepatic failure, and peritonitis; late consequences are subsequent deep venous thrombosis, thrombotic stroke, portal cavernoma, and esophageal variceal bleeding from portal hypertension.

\section{Risk factors}

Malignancy is the first independent risk factor for PVT, ${ }^{42}$ especially when of myeloid origin (chronic myeloid leukemia and myelofibrosis). Incidence among patients with myeloproliferative disease ranges from $13 \%$ to $18 \%{ }^{52}$ because hematological malignancy is usually associated with splenomegaly and therefore a dilated splenic vein and a hypercoagulable state.

Furthermore, the incidence of PVT correlates directly with splenic size. ${ }^{46,53-55}$ A large organ is associated with a greater diameter of the splenic vein. Once legated, the large splenic vein stump allows the formation of thrombi and serves as the origin for thromboembolic incidents. In our experience, when stratifying the patients by splenic weight, the rate of splenoportal thrombosis increased as the spleen size increased. In fact, patients with a splenic weight $>2.500 \mathrm{~kg}$ showed a rate of PSVT significantly higher $(P=0.02)$ compared with patients with a splenic weight ranging between $0.400 \mathrm{~kg}$ and $1.000 \mathrm{~kg}$. Patients with both splenic weight $>2.500 \mathrm{~kg}$ and myeloproliferative disorders had an $80 \%$ incidence of PSVT. Four patients (33\%) had postoperative thrombocytosis with a platelet count exceeding $1.000 \times 10^{9} / \mathrm{L}^{46}$

It is possible that early ligation of the splenic artery, use of an endoscopic vascular stapler, or distal or proximal ligation of the splenic vein could decrease PSVT risk, but their definitive role is controversial. In our study of laparoscopic splenectomies, hilar vessel section was performed much closer to the splenic parenchyma, without an increase of incidence of PSVT compared with the open studies $(P=\mathrm{NS}) .{ }^{46}$

Some authors showed a significantly higher incidence of PSVT after LS (8\%-52\%) compared with OS (10\%), but Ikeda et $\mathrm{al}^{54}$ and Winslow et $\mathrm{al}^{47}$ do not agree on this difference. The higher risk in LS can be due to decreased mesenteric flow caused by pneumoperitoneum (PVT has been observed even after other laparoscopic procedures, and Taura et $\mathrm{al}^{56}$ demonstrated that prolonged pneumoperitoneum causes lactic acid accumulation, most of all in patients with limited reserve capacity, leading to inadequate splanchnic tissue 


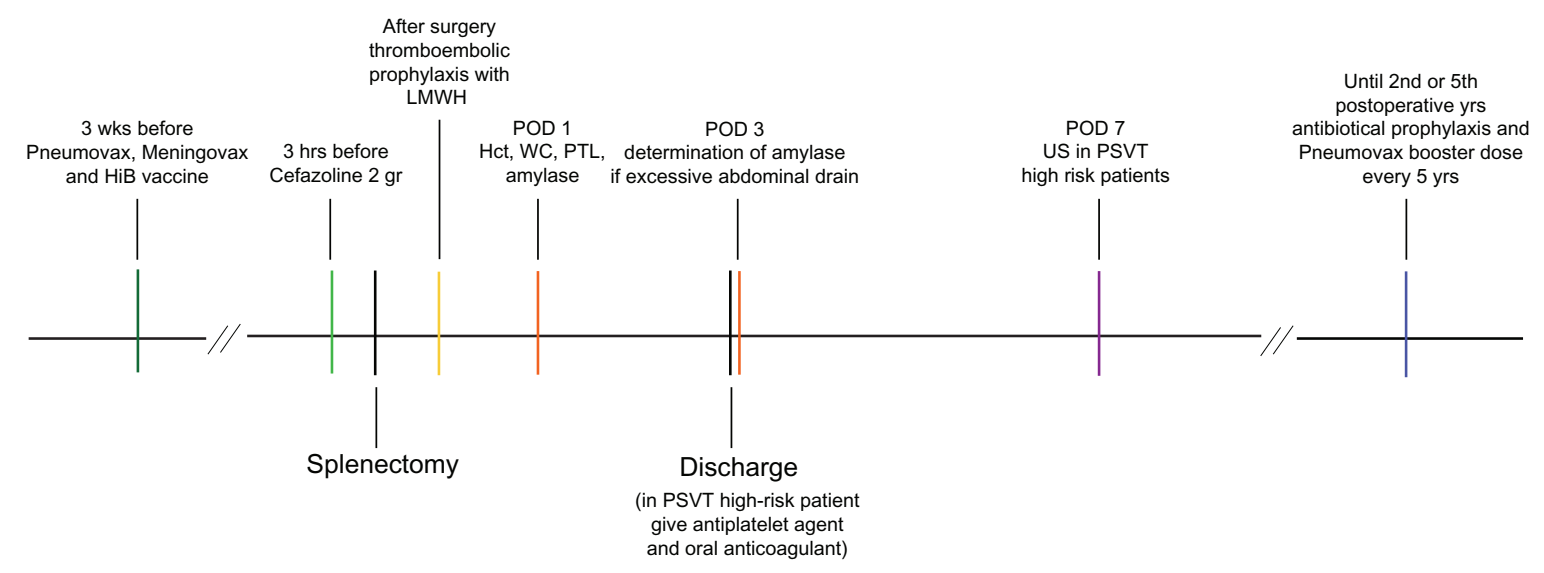

Figure I Timeline of proper management of splenectomy.

Abbreviations: WBC, white blood cell; PLT, platelet.

oxygenation) and probably by the reduced splenic outflow. Changes in intra-abdominal pressure during splenectomy reduce portal vein blood flow and induce stasis. Both stases of venous flow and resulting congested coagulation factors may induce PSVT, as reported by Baixauli et al. ${ }^{57}$ Our study shows that the two major differences between LS and OS within the operative technique ${ }^{46}$ were pneumoperitoneum and ligation of splenic hilar vessels. In the OS group, splenic hilar vessels were legated conventionally, and the structures were divided close to the splenic parenchyma with an endoscopic vascular stapler or with the LigaSure vessel sealings during LS.

Nevertheless, we perform laparoscopic procedures with no more than $12 \mathrm{mmHg}$ pneumoperitoneum, and considering a normal portal pressure at $10-12 \mathrm{mmHg}$, significant hemodynamic variation should not occur in these conditions. According to our experience, no differences of incidence of PSVT could be found between the two groups of patients.

Although platelet count and hypercoagulability can increase postoperatively, their role in the formation of thrombi is unknown. Infrequently, simultaneous undiagnosed clotting disorders may favor venous thrombosis and may even include extraportal segments such as the vena cava. The association between postsplenectomy thrombocytosis and portal vein thrombosis is unclear, because not all patients with thrombocytosis develop PSVT, and PSVT also occurs in patients with normal platelet counts. ${ }^{46}$ In a study of 129 patients with extreme thrombocytosis, thrombosis was found in 3.4\% of cases,${ }^{58}$ but a prospective observational study of patients with essential thrombocytopenia as compared with an age- and sex-matched control group failed to show an increased risk. ${ }^{59}$ In any case, early mobilization allowed by laparoscopic surgery is a great advantage against thrombotic risk. ${ }^{60}$ In Soyer et al's ${ }^{52}$ study, patients developing PSVT also showed high levels of hemoglobin and platelets. Although thrombocytosis is quite common in the postoperative period, Soyer et al underlined that altered platelet function is more meaningful than absolute platelet count. Furthermore, both quantitative and qualitative platelet abnormalities seem to be related to the development of thrombosis, but the absolute platelet count is less important than platelet function in the pathogenesis of thrombotic complications. Therefore, frequent monitoring of platelet levels should be carried out postoperatively, and antiplatelet therapy should be considered early in the course for highrisk patients.

In our experience, nevertheless, only four patients (33\%) showed postoperative marked thrombocytosis in the PSVT group. ${ }^{46}$

According to Soyer et al,${ }^{52}$ female gender and decreased levels of coagulation inhibitors are risk factors, because estrogen reduces peripheral vasodilatation capacity and erythrocyte membrane stability. These changes result in vascular stasis and a tendency for thrombosis. Soyer et al analyzed a pediatric population and established no sufficient data to assert this correlation, so further studies are required. They suggest that postpubertal girls should be more closely investigated for the development of PVT after splenectomy.

Deficiencies in natural inhibitors of coagulation (protein C and S, antithrombin III, lupus anticoagulant, factor V Leiden, prothrombin mutation, dysplasminogenemia) account for $72 \%$ of portal and hepatic vein thrombosis. ${ }^{47}$

According to our experience, even hemolytic anemia could be considered an independent risk factor, as it is not necessarily associated with splenomegaly and thrombocytosis, but this disease per se can increase the risk. According to our experience, we can say there were 12 cases of PSVT (7.6\%) among 158 patients: five of them had a myeloproliferative disorder (41.7\%), four (33\%) had hemolytic disease, and three $(25 \%)$ had lymphoproliferative disorder. ${ }^{46}$ 
Table I Early postoperative complications

\begin{tabular}{|c|c|c|c|c|c|}
\hline Study & No. of patients & Postoperative complication & Death & Major complications & $\overline{\text { Minor complications }}$ \\
\hline Targarona et a ${ }^{22}$ & 122 & $22(18 \%)$ & 0 & 0 & 22 \\
\hline Winslow et $\mathrm{al}^{47}$ & 101 & $8(8 \%)$ & I (I\%) & 0 & 8 \\
\hline Romano et $\mathrm{al}^{34}$ & 35 & $4(12 \%)$ & 0 & 0 & I \\
\hline Winslow and Brunt ${ }^{16}$ & 2119 & $16 \%$ & $1 \%$ & $1.6 \%$ & $14.4 \%$ \\
\hline Patel et $\mathrm{a}^{27}$ & 108 & $20(18.5 \%)$ & I (0.9\%) & 11 & 9 \\
\hline Boddy et $\mathrm{a}^{25}$ & 95 & $9(9.5 \%)$ & $2(2.1 \%)$ & 5 & 4 \\
\hline Romano et $\mathrm{al}^{46}$ & 158 & $25(15.82 \%)$ & 0 & 6 & 19 \\
\hline Casaccia et $\mathrm{al}^{24}$ & 309 & $56(18.1 \%)$ & 0 & 7 & 49 \\
\hline Mattioli et $\mathrm{a}^{40}$ & 85 & $2(2 \%)$ & 0 & 0 & 2 \\
\hline Rescorla et $\mathrm{al}^{39}$ & 231 & $26(11 \%)$ & 0 & 5 & 21 \\
\hline Casaccia et $\mathrm{al}^{32}$ & 676 & $138(20.4 \%)$ & $3(0.4 \%)$ & 26 & 109 \\
\hline Tran et $\mathrm{a}^{63}$ & 43 & 13 & 0 & 3 & 11 \\
\hline
\end{tabular}

In conclusion, the presence of splenomegaly and myeloproliferative disorders associated with hypercoagulopathy, hemolytic anemia, hypersplenism, and hematologic malignancy are high-risk factors for the development of PSVT. ${ }^{61}$ The rate of PSVT occurrence may be influenced by numerous other factors, such as technical details (early ligation of the splenic artery, use of the endoscopic vascular stapler, distal or proximal ligation of the splenic vein, pneumoperitoneum) or hematologic changes (postoperative elevation of the platelet count), but their role in the formation of thrombi is still unknown.

\section{Management}

Patients presenting one or more of the aforementioned risk factors need very careful surveillance for possible symptoms of PSVT, routine postoperative anticoagulation prophylaxis, and routine postoperative imaging even after hospital discharge. In our experience, low-dose subcutaneous unfractionated heparin prophylaxis is given to every patient with low-molecular-weight heparin (LMWH) (3000 U every 8 hours starting on the evening before the operation for at least 7 days). Patients presenting massive splenomegaly, hematologic risk factors, high postoperative thrombocytopenia, and myeloproliferative disease would benefit from postoperative routine surveillance imaging and more aggressive perioperative antithrombotic prophylaxis with $\mathrm{LMWH}^{46}$

The European Association for Endoscopic Surgery (EAES) recommends that perioperative anticoagulant prophylaxis with subcutaneous heparin should be applied to all patients, ${ }^{62}$ which is confirmed by the experience of Ikeda et al, ${ }^{48}$ who stated that the lack of thromboprophylaxis might have contributed to the remarkably high incidence in the study.

Tran et $\mathrm{al}^{63}$ administered unfractionated heparin intraoperatively or within 12 hours after surgery to every patient. For patients with either extremely low platelet counts or for whom there was a concern about hemostasis, thromboprophylaxis was discontinued when patients were discharged (postoperatively on day 1 or 2). In Tran et al's study there was no statistically significant difference in the incidence of PSVT between patients receiving thromboprophylaxis and those who did not.

Table 2 Incidence of the most common complications

\begin{tabular}{|c|c|c|c|c|c|c|c|c|}
\hline Study & Fever & $\begin{array}{l}\text { Pleural effusion } \\
\text { or BPN }\end{array}$ & $\begin{array}{l}\text { Wound } \\
\text { infection }\end{array}$ & PSVT & $\begin{array}{l}\text { Pancreatic } \\
\text { injuries }\end{array}$ & Bleeding & OPSI & Others \\
\hline Targarona et $\mathrm{al}^{22}$ & $3(13 \%)$ & $6(26 \%)$ & & & & $8(35 \%)$ & & $6(26 \%)$ \\
\hline Winslow et al ${ }^{47}$ & & & & 8 & & & & \\
\hline Romano et $\mathrm{al}^{34}$ & & & & 1 & & & 0 & \\
\hline Winslow and Brunt ${ }^{16}$ & & $3.1 \%$ & $1.7 \%$ & $0.9 \%$ & & $1.6 \%$ & & $3.7 \%$ \\
\hline Patel et $\mathrm{al}^{27}$ & & $8(7 \%)$ & 3 & I & & $6(6 \%)$ & 3 & 2 \\
\hline Boddy et $\mathrm{a}^{25}$ & & 2 & & & I & 4 & 0 & 2 \\
\hline Romano et al ${ }^{46}$ & 12 & 5 & I & $12(7.6 \%)$ & 0 & 4 & 0 & 2 \\
\hline Casaccia et $\mathrm{a}^{24}$ & 22 & 18 & 6 & 0 & 2 & 12 & 0 & 6 \\
\hline Mattioli et $\mathrm{al}^{40}$ & & I & & & I & & 0 & \\
\hline Rescorla et $\mathrm{al}^{39}$ & & 2 & 0 & I & 0 & 4 & 0 & 19 \\
\hline Casaccia et $\mathrm{a}^{32}$ & $16(11.6 \%)$ & $38(27.5 \%)$ & II (8\%) & $14(10.1 \%)$ & $5(3.6 \%)$ & $30(21.7 \%)$ & 0 & 24 (I7.3\%) \\
\hline Tran et $a^{63}$ & 1 & & & $9(22.5 \%)$ & 1 & & 0 & 2 \\
\hline
\end{tabular}

Abbreviations: BPN, bronchopneumonia; OPSI, overwhelming postsplenectomy infection; PSVT, portal or splenic vein thrombosis. 
Further studies are needed in order to delineate the thromboembolic risk in every patient and optimize prophylactic strategy in terms of indications, dosage, and duration. Although the impact of thrombocytosis on the incidence of PSVT is not yet clear, long-term antiplatelet therapy (acetylsalicylic acid) may be advisable in high-risk patients. Some authors have suggested the administration of antiplatelet agents (dipyridamole, aspirin) when severe thrombocytosis occurs postoperatively, especially for platelet counts higher than a million $\left(1000 \times 10^{3} / \mathrm{L}\right){ }^{64,65}$ Other authors recommend a threshold of $650 \times 10^{3} / \mathrm{L}$ to start administrating antiplatelet agents. ${ }^{66}$ In this case, prophylactic administration of subcutaneous heparin remains controversial. Some authors have found that such prophylaxis is insufficient to prevent PVT in high-risk patients and recommend a combination of heparin, antiplatelet agents, and oral warfarin after hospital discharge. ${ }^{42}$

Soyer et $\mathrm{al}^{52}$ suggest evaluating coagulation inhibitors and D-dimer levels, especially in those patients at high risk, eg, female with splenomegaly and myeloproliferative disease. Krauth et $\mathrm{l}^{49}$ also suggest screening for lupus anticoagulant in order to identify patients at risk for developing PSVT, especially in patients presenting elevated partial thromboplastin time.

Frequent monitoring of platelet levels should be carried out postoperatively. The optimal timing for image screening has not yet been defined, but in previous surveillance studies, it occurred from 3 days to 3 weeks postoperatively. $44,48,49,67-69$ Tran et a $1^{63}$ suggest that ultrasonographic screening on postoperative day 7 can indicate a higher incidence of PSVT (22\%), including all asymptomatic cases. This warrants routine surveillance with Doppler ultrasonography on postoperative day 7. Moreover, the authors showed that if asymptomatic PSVT does not develop at this time, it is unlikely to develop after 1 month, therefore subsequent screening at 1 month is not required. This implies that the major risk of thrombosis is perioperative due to clots formed in the splenic vein during or in the days following operation and embolized (rather than extended) into the portal vein system. ${ }^{48}$

Ikeda et $\mathrm{al}^{48}$ demonstrated that the incidence of PSVT found by using contrast-enhanced CT for screening is twice as high as most other studies using ultrasound.

According to a review by Krauth et $a 1,{ }^{49}$ the overall incidence of PSVT detected by imaging in prospective studies is $12.3 \%$ with a range of $4.8 \%-51.5 \%$. The highest incidences $(19.0 \%, 22.5 \%$, and $51.5 \%)$ were found in two prospective studies using CT imaging at 1 week and one study using ultrasonography repeated monthly for 6 months..$^{48,54,67}$

\section{Treatment}

The selection of patients in need of therapy is not clearly defined. The mere existence of a thrombus is not a sufficient reason to treat patients, especially if they are asymptomatic.

It is unclear whether all patients, even those with small asymptomatic intrahepatic portal vein thrombi, require anticoagulation, because some of them showed complete resolution without therapy. However, given the potential risk of complications related to progression and the relatively low risk of bleeding 1 week postoperatively, we believe that anticoagulation for patients diagnosed with perioperative PSVT is advisable.

In cases of mesenteric thrombus, an immediate anticoagulant therapy with intravenous heparin should be administered, followed by oral warfarin therapy at hospital discharge. ${ }^{70}$ In less severe cases, therapeutic doses of LMWH provide good results ( $90 \%$ recanalization if treated immediately). Local thrombolytic therapy with streptokinase or alteplase is a choice that is rarely necessary and rarely used by physicians.

All patients developing PSVT in our study were treated with intravenous heparin immediately upon diagnosis and switched to warfarin upon discharge. No patient received thrombolytic therapy or underwent thrombectomy. Our policy of treatment of patients with portal vein thrombosis has recently been modified by using high-dose LMWH instead of intravenous heparin. At follow-up, seven patients had successful portal vein recanalization, and all the patients were treated starting within 15 days after splenectomy; moreover, all portal veins remained patent in the cases responding to treatment. No patient developed the fatal complications of bowel necrosis or portal hypertension. ${ }^{46}$

Van't Riet et al ${ }^{71}$ demonstrated that all patients treated within 10 days after splenectomy had resolution of the clot, whereas no patient undergoing treatment more than 10 days after splenectomy presented clot resolution. In our experience, only those with early detection with immediate therapy of PSVT had recanalization of the veins.

Tran et $a l^{63}$ suggest treatment with oral warfarin for 3-6 months and ongoing anticoagulation management at the discretion of the hematologist.

Soyer et $\mathrm{al}^{52}$ treat PSVT in children by administering acetylsalicylic acid $1 \mathrm{mg} / \mathrm{kg} /$ day and LMWH subcutaneously 
$1 \mathrm{mg} / \mathrm{kg} /$ day for a mean duration of 10.5 days, in addition to broad spectrum antibiotics. In Soyer et al's pediatric study, thrombosis resolved in a mean period of 3 months and recanalization occurred in more than $90 \%$ of patients.

\section{Pancreas injury}

Pancreatic injury is one of the major and most severe complications after splenectomy, but incidence is as low as $1 \%-2 \%$. Katkhouda et $\mathrm{al}^{29}$ observed only two mild pancreatitis cases among 103 consecutive splenectomies. Chand et $\mathrm{al}^{72}$ reported an incidence of $15 \%$ for pancreatic injury, also including isolated hyperamylasemia, pancreatic fluid collection, pancreatic abscess, amylase-rich drain fluid, and atypical postoperative pain.

Common clinical findings of pancreatic injury are excessive and long-lasting abdominal pain, fever, and incisional erythema. Lab tests will show hyperamylasemia and leukocytosis, so a routine check of amylase levels and WC on postoperative day 1 is recommended. In those patients where abdominal drainage is placed, if abdominal drainage is more than expected or has the characteristic cloudy appearance of pancreatic juice, the amylase content of the drain effluent should be measured. ${ }^{60}$ In fact, large amounts of fluid in the splenic bed and left subphrenic space are associated with severe traumatic or vascular pancreatic injury or inadvertent resection of the tail of the pancreas.

Any suspicion must lead the surgeon to perform abdominal CT to investigate the presence of edema, peripancreatic fluid collection, subphrenic abscess, necrosis, and pancreatic pseudocyst. ${ }^{17}$ Abdominal CT is far superior than clinical evaluation and the other radiographic modalities and can be used for the initial diagnosis, follow-up studies, and for guiding the aspiration needle for further diagnostic examinations. Often, the complication appears as fluid collection in the left subphrenic space or may be found as swelling of the tail of the pancreas, ill-defined fluid collections, pancreatic fistula, a subphrenic abscess, or a well-encapsulated pancreatic pseudocyst. Liquefying hematomas, infected hematomas, and abscesses secondary to gastric and colon injury should be considered in the differential diagnosis. ${ }^{73}$

When the pancreatic duct or one of its branches is disrupted, either for traumatic or inflammatory reasons, a fistula can develop in communication either externally with the skin or, less frequently, internally with abdominal organs or peritoneal cavity. A fistula can lead to pancreatic fluid and electrolyte losses, bleeding, malabsorption, pulmonary problems, skin breakdown, and autodigestion or erosion of adjacent viscera, with a mortality rate ranging from $8 \%$ to $10 \%$, especially due to sepsis and bleeding. Collection is most often noted on postoperative days 3 and 4. Amylase-rich fluid is the most common sign. Pancreatic fistulas can be demonstrated if contrast material is injected at the time of the percutaneous aspiration.

\section{Risk factors}

Postoperative complications related to the pancreas are due to the configuration, location, and vascular supply of the tail of the pancreas. We have experienced a higher incidence of left subphrenic fluid collections after splenectomy than after other upper abdominal procedures, with higher and longer-lasting elevation of amylase levels in the immediate postsplenectomy drainage. ${ }^{73}$

Patients with splenomegaly present a significantly higher risk of sustaining a major pancreatic complication that may be due to technical difficulties. Chand et $\mathrm{al}^{72}$ report that splenomegaly seems to be the only associated risk factor for pancreatic injury that is not influenced by the learning curve of the surgical team. They suggest that early use of the hand-assisted technique may help to minimize the risk of pancreatic injury in cases of splenomegaly.

Risk of pancreatic injuries may increase in patients with lymphoma and hilar lymphadenopathy where the dissection plan is not clear and in patients experiencing intraoperative bleeding due to hilum lesions, leading to hemostasis procedures, which may cause pancreatic tail damage. Even misplacement of the linear stapler device for hilum control can increase the risk of pancreatic injuries, due to the stapler being placed too high. ${ }^{74}$ To prevent unintentional stapler damage, Vecchio et $\mathrm{al}^{17}$ suggest stopping hanging up the spleen just before firing the device, in order to allow the fall of the pancreatic tail away from the stapler line. Moreover the lateral approach is to be considered better than the anterior approach, as the pancreatic tail and the splenic hilum are more evident in the first case. This approach gives a clear view of the pancreas, as the tail near to the hilum automatically slides down due to gravity. ${ }^{19,75}$

\section{Management}

The first 72 hours are crucial to determine the patient's prognosis, since during this time span $30 \%$ of severe complications may occur. Segmental pancreatitis responds rapidly and without other complications to conservative medical therapy. Often, fluid replacement and nutrition support (total parenteral nutrition [TPN] for 4-6 weeks) can easily control 
minor pancreatic injuries in more than two-thirds of patients. Without early antibiotic treatment, the rate of pancreatic infection would be $40 \%-70 \%$, leading to necrosis after 1 week in $30 \%$ of cases. Therapy is based on imipenem or ciprofloxacin plus metronidazole.

Ninety percent of postoperative pancreatitis cases have a self-limited course of abdominal pain and hyperamylasemia for just 1 week. If these symptoms last longer, it means that the patient is experiencing ductal damage or peripancreatic necrosis, which can lead to the development of pseudocysts. Fluid collection must be drained by closed suction drainage for at least 4 days. If there is a fistula $(>50 \mathrm{~mL} /$ day of amylaserich fluid draining from the percutaneous drain), the patient must be treated through endoscopic retrograde cholangiopancreatography, then monitored by CT and, if CT is negative, drainage can be removed. However, if the fluid collection is increasing, percutaneous and/or surgical drainage procedures are necessary. A fistula must be surgically closed only when the daily output is $>200 \mathrm{~mL} /$ day. Most cases of low output fistula ( $<200 \mathrm{~mL} /$ day) can be treated with drainage, resuscitation with isotonic crystalloid solution, bowel rest, TPN, and correction of metabolic acidosis related to bicarbonate loss. Approximately $80 \%$ of external pancreatic fistula and $40 \%-60 \%$ of internal pancreatic fistula close spontaneously due to somatostatina and its analogs, such as octreotide, which can reduce basal and stimulated pancreas secretion if given in doses as small as $50 \mu \mathrm{g}$ twice a day. ${ }^{20,76}$

Postsplenectomy necrotizing pancreatitis is a very rare complication and must be treated promptly. Surgical removal of necrotic tissue decreases mortality (50\%-80\% without necrosectomy, $10 \%-40 \%$ with necrosectomy). Diagnosis can be made after evaluation of contrast-enhanced CT (nonenhancing area among pancreatic tissue and peripancreatic fat) and after percutaneous needle aspiration. If this test shows a sterile collection, necrosectomy may not be necessary. Necrosis must be less than $50 \%$. Necrosectomy must be performed if intensive care unit management (mechanical ventilation, hemofiltration, hemodialysis) is not enough.

\section{Other complications}

Subphrenic abscess is relatively common. Serosanginous fluid or fluid from a pancreatic fistula can be collected in the subphrenic space and become infected. Patients often present with a swinging fever and leukocytosis, and often have a reactive effusion in the left chest. Less common symptoms include hiccups from subdiaphragmatic irritation. Resolution is commonly achieved with a combination of percutaneous drainage and appropriate antibiotics. ${ }^{60}$
ACS is a complication verified only in patients affected by SCD, occurring at a rate of $5.2 \%$ of patients undergoing LS and $33.3 \%$ if the open technique is applied. The exact etiology of ACS is unknown. Multiple factors have been proposed, including infection due to the lower immunocompetence of the SCD patient, in situ thrombosis from intraoperative site manipulation, hypoventilation secondary to chest pain, and pulmonary fat embolism. ACS can occur within the first 24 hours or even 1 month postoperatively. ${ }^{77}$ In these patients, even vaso-occlusive pain crises, stroke, or an abnormal transcranical Doppler (24\%) are quite frequent, as reported by Kalpatthi et $\mathrm{al}^{78}$ Late complications are tied to pathological processes that start to develop right after the surgery, eg, cavernoma and esophageal varices caused by unrecognized PSVT, incisional hernia, and peritoneal adhesive band.

Splenectomy leads to hematologic and immunologic alteration, which can occur either right after the surgery or even years later. Whereas the first group includes platelet count increases due to splenic sequestration, the presence of erythrocyte abnormalities (ie, Howell-Jolly bodies), and ACS in SCD patients, the second group involves higher susceptibility to capsulated bacteria (overwhelming postsplenectomy infection [OPSI]) and hematological parasites.

\section{OPSI}

OPSI is a rare but life-threatening complication of splenectomy. OPSI is usually caused by the encapsulated bacteria Streptococcus pneumoniae, Haemophilus influenzae, and Neisseria meningitidis. Other pathogens in such infections may include bacteria such as Escherichia coli and Pseudomonas aeruginosa, Capnocytophagia canimorsus, group B streptococci, Enterococcus spp, Ehrlichia spp, and protozoa such as the Plasmodium spp.

Bisharat et $\mathrm{al}^{79}$ showed an incidence of $3.2 \%$ for invasive infection and an overall mortality of $1.4 \%$ among adult patients and in $1.7 \%$ of children who underwent splenectomy. ${ }^{80}$ In their review, the mean interval between splenectomy and infection was 22.6 months. The incidence of infection was higher for patients with thalassemia major $(8.2 \%)$ and sickle cell anemia (7.3\%) than for patients with idiopathic thrombocytopenia (2.1\%), and higher in children with thalassaemia major (11.6\%) and sickle cell anemia $(8.9 \%)$ than in adults with the same diseases $(7.4 \%$ and $6.4 \%$, respectively). ${ }^{79}$ Moreover, those patients who underwent splenectomy because of hemolytic anemia are regarded to be at a greater risk of OPSI, probably because the reticuloendothelial system works with a limited functional reserve. ${ }^{80}$ 
The most reliable incidence data are probably those of Schwartz et al, ${ }^{81}$ who found a risk of fulminant infection in one case per 500 person-years of observation.

Whereas some studies indicate that the risk of OPSI declines with time elapsed since splenectomy,${ }^{82}$ the estimated incidence rate is $0.8 \%-0.42 \%$ per year with a lifetime rate of $5 \%$. OPSI carries a mortality rate of $38 \%-69 \%{ }^{83}$

\section{Risk factors}

The main risk factors are the age at which splenectomy occurs, with children younger than 2 years and the elderly being particularly at risk; the immunosuppression of patients; the reason leading to splenectomy, especially diseases where splenic function is compromised (eg, SCD); and the time interval after splenectomy (most cases occur within 2 years). The risk arises also in those who present another cause for immunosuppression, such as corticosteroids or cytotoxics. ${ }^{83}$

\section{Management}

Guidelines published by the British Committee for Standards in Hematology emphasized that most infections after splenectomy could be avoided through measures that include offering patients appropriate and timely immunization, antibiotic prophylaxis, education, and prompt treatment of infection. ${ }^{84}$

The first step is to administer, 3 weeks prior to surgery, antipneumococcal vaccination with Pneumo $23^{\circledR}$ (SanofiPasteur, Lyon, France) with 23 antigens (to be repeated 3-5 or 5-10 years later), antimeningococcal vaccination with Mencevax ${ }^{\circledR}$ ACWY (SmithKline Beecham, Brentford, Middlesex, UK) with four antigens, and antihemofilus influenzae with Hiberix ${ }^{\circledR}$ antihemophilus influenzae B (SmithKline Beecham). Although there are no data confirming the optimum timing of the vaccine given postoperatively when LS is performed as an emergency, it is logical to give it at the time of discharge. Pneumococcal vaccine failures should be anticipated, either because of strains not included in the vaccine or because of poor vaccine-induced antibody response as a consequence of the splenectomy or underlying disease.

Annual influenza vaccination is also recommended for asplenic individuals. All of the vaccines listed can be given together, if necessary. ${ }^{83}$ Then 3 hours before surgery, a preoperative antibiotic prophylaxis of cefazoline $2 \mathrm{~g}$ or clindamycin $900 \mathrm{mg}$ is administered to the patient. According to the EAES guidelines, preoperative prophylaxis should be followed by intravenous amoxicillin (alternatively, erythromycin) administration. ${ }^{62}$

Not all authors agree on the need to proceed with a long-term antibiotic prophylaxis. Some suggest the use of penicillin $\mathrm{V}$ for 2 years in the adult patient and for 5 years in the pediatric patient. However, long-term antibiotic therapy may be a risk factor for the selection of resistant strains, and efficacy may be reduced by noncompliance. On the other hand, all cases of OPSI reported in the literature are due to noncompliance of patients or splenectomized children's parents, such as the 9-year-old thalassemic child reported by Durakbasa et al. ${ }^{80} \mathrm{In}$ this case, the postmortem inquiry revealed that after being sent home following the operation, the patient had not been given any penicillin medication. In the same study, a boy with elliptocytosis died of overwhelming postsplenectomy sepsis 6 years after the operation while still on penicillin prophylaxis.

Penicillin provides prophylaxis only against sensitive pneumococci, meningococci, and streptococci, but it is suitable only for adults at $500 \mathrm{mg}$ daily or twice a day. Amoxicillin is a preferred choice in children. Macrolides do not represent a suitable alternative of antibiotic resistance. For example, currently, $12 \%$ of pneumococci in UK are resistant to macrolides. In penicillin-allergic individuals, alternatives are either cotrimoxazole or a fluoroquinolone with Grampositive activity such as moxifloxacin. ${ }^{83}$

Every splenectomized patient needs to be accurately informed. The first signs of developing OPSI are similar to those of influenza (fever, headache, vomiting) followed by bacteremic shock and disseminated intravascular coagulation. Death may occur within 6 hours of the onset of initial prodromal symptoms. Patients should have a 5-day supply of antibiotics ready to take at home at the onset of symptoms. ${ }^{60}$

\section{Treatment}

In case of infection symptoms and fever higher than $38^{\circ} \mathrm{C}$, early antibiotic therapy with amoxicillin clavulanate $625 \mathrm{mg}$ 8 hourly (cefuroxime $250 \mathrm{mg} 12$ hourly if rash with penicillin or if serious allergic reaction to cotrimoxazole or moxifloxacin) should be administered. Where there is a high prevalence of penicillin-resistant pneumococci (minimal inhibitory concentration $>1 \mathrm{mg} / \mathrm{L}$ ), linezolid $600 \mathrm{mg}$ 12-hourly would be suitable. Should it not be enough, hospitalization should be planned.

In hospital, the patient should be resuscitated and managed in the intensive therapy unit. First of all, a sample for blood cultures must be taken. A combination of antibiotics should be given to cover the wide spectrum of bacteria implicated, such as ceftriaxone plus vancomycin or teicoplanin (plus rifampicin if highly resistant pneumococci are prevalent). A peripheral blood or buffy coat film should be examined immediately for the presence of circulating or intraleukocytic bacteria. If Gram-negative rods are seen, cover for Pseudomonas should be added. The presence of intracellular bacteria or morulae 
within leukocytes (suggestive of ehrlichiosis) and intraerythrocytic parasites (malaria or babesiosis) should be sought. Blood cultures are positive in $95 \%$ of cases of OPSI, and antibiotics can be modified once the cultures are available. As well as intravenous antibiotics, Davidson and Wall ${ }^{83}$ advise intravenous immunoglobulin $0.4 \mathrm{~g} / \mathrm{kg}$ daily for 3 days.

Newland ${ }^{85}$ underlines that in his experience he has noted that only a very low rate of patients (13\%) received all three vaccines before elective splenectomy and suggests that each patient undergoing splenectomy should carry a letter or a card to signal their status. Kyaw et $\mathrm{al}^{86}$ showed that only half of patients received information about antibiotics prophylaxis.

For immunologic functions to be preserved, 25\% of a normal spleen by weight for the respective patient age must be retained with adequate arterial perfusion. ${ }^{87}$ In the 1970 s and 1980s, partial splenectomy (PS) was presented as an effective way to avoid OPSI. During the surgical procedure for hematologic diseases, $75 \%-80 \%$ of the splenic tissue was removed. When PS was performed for focal splenic tumors, the splenic remnant was around $70 \%{ }^{88}$ In Vicka et al's ${ }^{89}$ study, PS proved to be not only safe but also effective for the control of splenic sequestration in patients with SCD (in those patients, the upper pole was preserved with blood supply off the main splenic artery). Vicka et al's study was composed of few patients, and the results were not compared with total splenectomy cases, so it does not have any statistical significance. In the end, although it could be considered a means to avoid OPSI, PS should be avoided because of its poor long-term effectiveness and high recurrence rate of hematologic disease. Moreover, this technique does not abolish the risk of gallstone formation in patients suffering from hemolytic anemia. ${ }^{80}$

There are a few cases where PS could be the best compromise, eg, children younger than 2 years who are unable to be vaccinated or patients living in countries where antipneumococcal vaccination is not available. ${ }^{62}$

\section{Conclusion}

It is very important that patients get an accurate evaluation immediately after surgery and at time of discharge, in order to avoid underestimating any sign or symptom indicating complications, especially considering the short hospitalization period, which is a great advantage allowed by LS but could cause the underestimation of anomalies in physical examination and in lab tests.

Some authors suggest monitoring patients, paying attention not only to the most common major and minor complications (pleural effusion, atelettasia, BPN, wound infection, pancreatitis) but also to the potentially life-threatening, even if rare, complications PSVT and OPSI.
The patient should be accurately informed about all risks, be prepared to identify new symptoms that could arise at home, and share information with their family doctor.

Patients undergoing splenectomy (Figure 1) should be treated with a preoperative antibiotic prophylaxis of cefazolin $2 \mathrm{~g}$ and a perioperative thromboembolic prophylaxis LMWH (3,000 U every 8 hours starting on the evening before the operation and for at least 7 days). In PSVT high-risk patients, a combination of heparin, antiplatelet agents, and oral warfarin after hospital discharge is recommended, added to routine postoperative surveillance imaging with Doppler ultrasonography on postoperative day 7 .

A routine check of amylase levels, WC, and PTL on postoperative day 1 is recommended and, in patients with abdominal drainage, the amylase content of the drain effluent should be measured in case of suspicion of pancreatic injury. If patients present this symptom or any other symptoms that potentially suggests pancreas injury, a CT should be performed.

In case of mesenteric thrombus, an immediate anticoagulant therapy with intravenous heparin should be administered, followed by oral warfarin therapy at hospital discharge. ${ }^{70}$ In less severe cases, therapeutic doses of LMWH provide good results (90\% recanalization if treated immediately). Local thrombolytic therapy with streptokinase or alteplase is not usually a necessary choice and is rarely used by physicians.

Finally, the Working Party of the Clinical Hematology Task Force has produced the following guidelines for the prevention of OPSI:

- Pneumovax protection from $S$. pneumoniae: repeat every 5 years (children younger than 2 years need a modified vaccine)

- HiB vaccine protection from $H$. influenzae

- Meningovax protection from N. meningitides

- Influenza vaccine annually may reduce secondary pneumococcal and $H$. influenzae infections

- Antibiotics: postoperatively, children up to 16 years old should be offered long-term antibiotics such as phenoxymethylpenicillin or amoxicillin. For adults, the data are less clear. Adults are currently given antibiotics such as phenoxymethylpenicillin or amoxicillin for 2 years postoperatively. Patients who are allergic to penicillin should be offered erythromycin. ${ }^{60}$

Moreover, patients must be accurately informed of any risk they could encounter and about what to do in case of infection. If patients present OPSI symptoms, they must be hospitalized and a combination of antibiotics should be given to cover the wide spectrum of bacteria implicated, such as ceftriaxone plus vancomycin or teicoplanin. 


\section{Disclosure}

The authors report no conflicts of interest in this work.

\section{References}

1. Musser G, Lazar G, Hocking W, Busuttil RW. Splenectomy for hematologic disease. Ann Surg. 1984;200:40-45.

2. Dawson AA, Jones PF, King DJ. Splenectomy in the management of hematologic disease. Br J Surg. 1987;74:353-357.

3. Johansson T, Bostrom H, Sjodhal R, Ihse I. Splenectomy for hematological diseases. Acta Chirurgica Scandinavica. 1990;156:83-86.

4. Wilhelm MC, Jones RE, McGhee R, Mitchener JS, Sandusky WR, Hess CE. Splenectomy in hematologic disorders. Ann Surg. 1988;207: 581-589.

5. Marble KR, Deckers PJ, Kern KA. Changing role of splenectomy for hematologic disease. J Surg Oncol. 1993;52:169-171.

6. Johnson HA, Deterling RA. Massive splenomegaly. Surgery Gynecology and Obstetrics. 1989;168:132-137.

7. Coon WW. Splenectomy for massive splenomegaly. Surgery Gynecology and Obstetrics. 1989;169:235-237.

8. Malmaeus J, Akre T, Adami HO, Hagberg H. Early postoperative course following elective splenectomy in haematological disease a high complication rate in patients with myeloproliferative disorders Br J Surg. 1986;73:720-723.

9. Horowitz J, Smith JL, Weber TK, Rodriguez-Bigas MA, Petrelli NJ. Postoperative complications after splenectomy for hematologic malignancies. Ann Surg. 1996;3:290-296.

10. Coon WW, Liepman MK. Splenectomy for agnogenic myeloid metaplasia. Surg, Gynecol Obstet. 1982;154:561-563.

11. Mentzer SJ, Fletcher Starnes H, Canellos G, et al. Splenic enlargement and hyperfunction as indications for splenectomy in chronic leukemia. Ann Surg. 1997;205:13-17.

12. Coon WW. Splenectomy for thrombocytopenia due to secondary hypersplenism. Arch Surg. 1988;123:369-371.

13. Matteoti R, Assalia A, Pomp A. Splenectomy. In: Ahmed A, Gagner M, Schein M, editors. Controversies in Laparoscopic Surgery. 1st ed. Berlin, Germany: Springer-Verlag; 2006:299-314 [Chat. 24].

14. Decker G, Millat B, Guillon F, et al. Laparoscopic splenectomy forbenign and malignant hematologic diseases: 35 consecutive cases. World J Surg. 1998;22:1-7.

15. Balague C, Targarona EM, Cerda G, Novell J, Montero O, Bendahan G, et al. Long-term outcome after laparoscopic splenectomy related to hematologic diagnosis. Surg Endosc. 2004;18:1283-1287.

16. Winslow ER, Brunt LM. Perioperative outcomes of laparoscopic vs open splenectomy: a methanalysis with emphasis on complications. Surgery. 2003;134:647-665.

17. Vecchio R, Gelardi V, Intagliata E, Barbaros U, Cacciola RR, Cacciola E. How to prevent intraoperative risks and complications in laparoscopic splenectomy. G Chir. 2010;31(1-2):55-61.

18. Danielson PD, Shaul DB, Phillips JD, et al. Technical advances in pediatric laparoscopy have had a beneficial impact on splenectomy. J Pediatr Surg. 2000;35:1578-1581.

19. Sharma D, Shukla VK. Laparoscopic splenectomy 16 years since delaitre with review of current literature. Surg Laparosc Endosc Percutan Tech. 2009;19:190-194.

20. Golematis BC, Gomatos IP, Konstadoulakis MM. Complications of splenectomy. In: Hakim NS, Papalois VE, editors. Surgical complications: diagnosis and treatment. London, UK: Imperial College Press, 2007; p. 467.

21. Kercher KW, Matthews BD, Walsh M, Sing RF, Backus CL, Heniford T. Laparoscopic splenectomy for massive splenomegaly. The American Journal of Surgery. 2002;183:192-196.

22. Targarona EM, Espert JJ, Bombuy E, et al. Complications of Laparoscopic Splenectomy. Arch Surg. 2000;135:1137-1140.

23. Cusick RA, Waldhausen JHT. The learning curve associated with pediatric laparoscopic splenectomy. The American Journal of Surgery. 2001;181:393-397.
24. Casaccia M, Torelli P, Squarcia S, et al; for IRLSS Centers. Laparoscopic splenectomy for hematologic diseases: a preliminary analysis performed on the Italian Registry of Laparoscopic Surgery of the Spleen (IRLSS). Surg Endosc. 2006;20:1214-1220.

25. Boddy AP, Mahon D, Rhodes M. Does open surgery continue to have a role in elective splenectomy? Surg Endosc. 2006;20:1094-1098.

26. Targarona EM, Espert JJ, Cerda'n G, Balague C, Piulachs J, Sugranes G, et al. Effect of spleen size on splenectomy outcome. A comparison of open and laparoscopic surgery. Surg Endosc. 1999;13:559-562.

27. Patel AG, Parker JE, Wallwork B, Kau KB. Massive splenomegaly is associated with significant morbidity after laparoscopic splenectomy. Annals of Surgery. 2003;238:235-240.

28. McAneny D, LaMorte WW, Scott TE, et al. Is splenectomy more dangerous for massive spleens? Am J Surg. 1998;175:102-107.

29. Katkhouda N, Hurwitz MB, Rivera RT, et al. Laparoscopic splenectomy: outcome and efficacy in 103 consecutive patients. Ann Surg. 1998;228: $568-578$.

30. Shimomatsuya T, Horiuchi T. Laparoscopic splenectomy for treatment of patients with idiopathic thrombocytopenic purpura. Comparison with open splenectomy. Surg Endosc. 1999;13:563-566.

31. Casaccia M, Torelli P, Squarcia S, et al. Laparoscopic splenectomy for hematologic diseases: a preliminary analysis performed on the Italian Registry of Laparoscopic Surgery of the Spleen (IRLSS). Surg Endosc. 2006;20:1214-1220.

32. Casaccia M, Torelli P, Pasa A, Sormani MP, Rossi E; IRLSS Centers. Putative Predictive Parameters for the Outcome of Laparoscopic Splenectomy: A Multicenter Analysis Performed on the Italian Registry of Laparoscopic Surgery of the Spleen. Annals of Surgery. 2010;251:287-291.

33. Targarona EM, Balague C, Trias M. Is laparoscopic approach reasonable in cases of splenomegaly? Semin Laparosc Surg. 2004;11:185-190.

34. Romano F, Caprotti R, Franciosi C, De Fina S, Colombo G, Uggeri F. Laparoscopic splenectomy using ligasure Preliminary experience. Surg Endosc. 2002;16:1608-1611.

35. Romano F, Caprotti R, Franciosi C, De Fina S, Colombo G, Sartori P, et al. The use of LigaSure during pediatric laparoscopic splenectomy: a preliminary report. Pediatr Surg Int. 2003;19:721-724.

36. Gelmini R, Romano F, Quaranta N, Caprotti R, Tazzioli G, Colombo G, et al. Sutureless and stapleless laparoscopic splenectomy using Radiofrequency LigaSure device. Surg Endosc. 2006;20:991-994.

37. Keidar A, Feldman M, Szold A. Analysis of outcome of laparoscopic splenectomy for idiopathic thrombocytopenic purpura by platelet count. Am J Hematol. 2005;80:95-100.

38. Dominguez EP, Choi YU, Scott BG, et al. Impact of morbid obesity on outcome of laparoscopic splenectomy. Surg Endosc. 2007;21:422-426.

39. Rescorla FJ, West KW, Engum SA, Grosfeld JL. Laparoscopic Splenic Procedures in Children: Experience in 231 Children. Annals of Surgery. 2007;246:683-688.

40. Mattioli G, Pini Prato A, Cheli M, Esposito C, Garzi A, LiVoti G, et al. Italian multicentric survey on laparoscopic spleen surgery in the pediatric population. Surg Endosc. 2007;21:527-531.

41. Caprotti R, Porta G, Franciosi C, et al. Laparoscopic splenectomy for hematological disorders. Our experience in adult and pediatric patients. Int Surg. 1998;83:303-307.

42. Targarona EM. Portal vein thrombosis after laparoscopic splenectomy: the size of the risk. Surg Innov. 2008;15:266-270.

43. Broe PJ, Conley CL, Cameron JL. Thrombosis of the portal vein following splenectomy for myeloid metaplasia. Surg Gynecol Obstet. 1981;152:488-492.

44. Petit P, Bret P, Atri M, et al. Splenic vein thrombosis after splenectomy: frequency and role of imaging. Radiology. 1994;190:65-68.

45. Loring LA, Panicek DM, Karpeh MS. Portal system thrombosis after splenectomy for neoplasm or chronic hematologic disorder: is routine surveillance imaging necessary? J Comput Assist Tomogr. 1998;22: 856-860.

46. Romano F, Caprotti R, Conti M, et al. Thrombosis of the splenoportal axis after splenectomy. Langenbecks Arch Surg. 2006;391:483-488.

47. Winslow ER, Brunt LM, Drebin JA, Soper NJ, Klingensmith ME. Portal vein thrombosis after splenectomy. Am J Surg. 2002;184:631-636. 
48. Ikeda M, Sekimoto M, Takiguchi S, et al. High incidence of thrombosis of the portal venous system after laparoscopic splenectomy: a prospective study with contrast-enhanced CT scan. Ann Surg. 2005; 241:208-216.

49. Krauth MT, Lechner K, Neugebauer EAM, et al. The postoperative splenic/portal vein thrombosis after splenectomy and its prevention: an unresolved issue. Haematologica. 2008;93:1227-1232.

50. Ikeda M, Sekimoto M, Takiguchi S, et al. Letters to the editor. Ann Surg. 2005;242:756

51. Gertsh P, Matthews J, Lerut J, et al. Acute thrombosis of the splanchnic veins. Arch Surg. 1993;128:341-345.

52. Soyer T, Ciftci AO, Tanyel FC, Enocak MESS, Büyükpamukc N. Portal vein thrombosis after splenectomy in pediatric hematologic disease: risk factors, clinical features, and out come. J Ped Surg. 2006;41:1899-1990.

53. Svensson M, Wiren M, Kimby E, Hagglund H. Portal vein thrombosis is a common complication following splenectomy in patients with malignant haematological diseases. Eur J Haematol. 2006;77:203-209.

54. Ikeda M, Sekimoto M, Takiguchi S, et al. Total splenic vein thrombosis after laparoscopic splenectomy: a possible candidate for treatment. Am J Surg. 2007;193:21-25.

55. Fujita F, Lyass S, Otsuka K, et al. Portal vein thrombosis following splenectomy: identification of risk factors. Am Surg. 2003;69:951-956.

56. Taura P, Lopez A, Lacy AM, et al. Prolonged pneumoperitoneum at 15 mmHg causes lactic acidosis. Surg Endosc. 1998;12:198-201.

57. Baixauli J, Delaney CP, Senagore AJ, Remzi FH, Fazio VW. Portal vein thrombosis after laparoscopic sigmoid colectomy for diverticulitis: report of a case. Dis Colon Rectum. 2003;46:550-553.

58. Buss DH, Stuart JJ, Lipscomb GE. The incidence of thrombotic and hemorrhagic disorders in association with extreme thrombocytosis: an analysis of 129 cases. Am J Hematol. 1985;20:365-372.

59. Ruggeri M, Finazzi G, Tosetto A, Riva S, Rodeghiero F, Barbui T. No treatment for low-risk thrombocytemia: results from a prospective study. Br J Haematol. 1998;103:772-777.

60. Lloyd DM, Strickland AD. Surgery of the spleen. Hepatobiliary Surgery ii. 2010;28(5):229-233.

61. Ikeda M, Sekimoto M, Takiguchi S, et al. Total splenic vein thrombosis after laparoscopic splenectomy: a possible candidate for treatment. Am J Surg. 2007;193:21-25.

62. Habermal B, Sauerland S, Decker G, et al. Laparoscopic splenectomy: the clinical practice guidelines of the European Association for Endoscopic Surgery (EAES). Surg Endosc. 2008;22:821-848.

63. Tran T, Demyttenaere SV, Polyhronopoulos G, et al. Recommended timing for surveillance ultrasonography to diagnose portal splenic vein thrombosis after laparoscopic splenectomy. Surg Endosc. 2010;24:1670-1678.

64. Ruiz-Tovar J, Perez De Oteyza P, Blazquez J, et al. Portal vein thrombosis after laparoscopic splenectomy in benign hematologic diseases. J Laparoendosc Adv Surg Tech. 2007;17:448-454.

65. Grieshammer M, Bangerter M, SauerT, Wennauer R, Bergmann L, Heimpel H. Aetiology and clinical significance of thrombocytosis: Analysis of 732 patients with an elevated platelet count. J Intern Med. 1999;245:295-300.

66. Stamou KM, Toutouzs KG, Kelets PG, et al. Prospective study of the incidence and risk factors of postsplenectomy thrombosis of the portal, mesenteric, and splenic veins. Arch Surg. 2006;141:663-669.

67. Pietrabissa A, Moretto C, Antonelli G, et al. Thrombosis in the portal venous system after elective laparoscopic splenectomy. Surg Endosc. 2004; $18: 1140-1143$.

68. Hassn A, Al-Fallouji MA, OufTI, et al. Portal vein thrombosis following splenectomy. Br J Surg. 2000;87:362-373.

Open Access Surgery

\section{Publish your work in this journal}

Open Access Surgery is an international, peer-reviewed, open access journal that focuses on all aspects of surgical procedures and interventions. Patient care around the peri-operative period and patient outcomes post surgery are key topics. All grades of surgery from minor cosmetic interventions to major surgical procedures are covered. Novel techniques Submit your manuscript here: http://www.dovepress.com/open-access-surgery-journal
69. Loring LA, Panicek DM, Karpeh MS. Portal system thrombosis after splenectomy for neoplasm or chronic hematologic disorder: is routine surveillance imaging necessary? J Comput Assist Tomog. 1998;22: 856-860.

70. Condat B, Pessione F, Denninger MH, et al. Recent portal or mesenteric venous thrombosis: increased recognition and frequent recanalization on anticoagulant therapy. Hepatology. 2000;32:466-470.

71. Van't Riet M, Burger JW, van Muiswinkel JM, et al. Diagnosis and treatment of portal vein thrombosis following splenectomy. Br J Surg. 2000;87:1229-1233.

72. Chand B, Walsh RM, Ponsky J, Brody F. Pancreatic complications following laparoscopic splenectomy. Surg Endosc. 2001;15:1273-1276. Epub 2001 Sep 4.

73. Balthazar EJ, Megibow A, Rothberg M, Lefleur RS. CT Evaluation of Pancreatic Injury Following Splenectomy. Gastrointest Radiol. 1985;10:139-144.

74. Trías AP, Targarona EM. Laparoscopic surgery of the spleen: state of the art. Langenbeck's Arch Surg. 2001;386:230-239.

75. Targarona EM, Espert JJ, Balaguè C, Piulachs J, Artigas V, Trias M. Splenomegaly should not be considered a contraindication for laparoscopic splenectomy. Ann Surg. 1998;228:35-39.

76. Saber AA, Helbling B, Khaghany K, Nirmit G, Pimental R, McLeod MK. Safety zone for splenic hilar control during splenectomy: a computed tomography scan mapping of the tail of the pancreas in relation to the splenic hilum. Am Surg. 2007;73:890-894.

77. Ghantous S, Mulhim SA, Faris NA, Abushullaih BA, Shalak F, Yazbeck S. Acute chest syndrome after splenectomy in children with sickle cell disease. J Ped Surg. 2008;43:861-864.

78. Kalpatthi R, Kane ID, Shatat IF, Rackoff B, Disco D, Jackson SM. Clinical events after surgical splenectomy in children with sickle cell desease. Pediatr Surg Int. 2010;26:495-500.

79. Bisharat N, Omari H, Lavi I, Raz R. Risk of infection and death among post-splenectomy patients. $J$ Infect. 2001;43:182-186.

80. Durakbasa CU, Timur C, Sehiralti V, Mutus M, Tosyali N, Yoruk A. Pediatric splenectomy for hematological diseases: outcome analysis. Pediatr Surg Int. 2006;22:635-639.

81. SchwartzPE, SterioffS, Mucha P, Melton LJ3rd, Offord KP. Postsplenectomy sepsis and mortality in adults. JAMA. 1982;248:2279-2283.

82. Lynch AM, Kapila R. Overwhelming postsplenectomy infection. Infect Dis Clin North Am. 1996;10:693-707.

83. Davidson RN, Wall RA. Prevention and management of infections in patients without a spleen. Clin Microbiol Infect. 2001;7:657-660.

84. Guidelines for the prevention and treatment of infection in patients with an absent or disfunctional spleen. Working Party of the British Committee for Standards in Haematology Clinical Haematology Task Force. BMJ. 1996;312:430-434.

85. Newland A. Preventing severe infection after splenectomy. BMJ. 2005; 331:417.

86. Kyaw MH, Holmes EM, Chalmers J, Jones IG, Campbell H. A survey of vaccine coverage and antibiotic prophylaxis in splenectomised patients in Scotland. J Clin Pathol. 2002;55:472-474.

87. Uranues S, Grossman D, Ludwig L, Bergamaschi R. Laparoscopic partial splenectomy. Surg Endosc. 2007;21:57-60.

88. Henry G, Becmeur F, Me' fat L, Kalfa D, Lutz P, Lutz L, et al. Laparoscopic Partial Splenectomy: Indications and results of a multicenter retrospective study. Surg Endosc. 2008;22:45-29.

89. Vicka LR, Goscheb JR, Islamc S. Partial splenectomy prevents splenic sequestration crises in sickle cell disease. J Pediatr Surg. 2009;44:2088-2091.

\section{Dovepress}

and the utilization of new instruments and materials, including implants and prostheses that optimize outcomes constitute major areas of interest. The manuscript management system is completely online and includes a very quick and fair peer-review system. Visit http://www.dovepress.com/ testimonials.php to read real quotes from published authors. 